\title{
STUDIES OF WATER MOVEMENTS AND WINDS AT VARIOUS LIGHTVESSELS \\ II. AT THE SEVEN STONES LIGHTVESSEL NEAR THE SCILLY ISLES
}

\author{
By J. N. Carruthers, D.Sc., F.Inst.P, ${ }^{1}$ \\ Commander A. L. Lawford, R.N. (rtd.) ${ }^{1}$ \\ and Instructor-Lieutenant V. F. C. Veley, B.A., R.N. ${ }^{2}$ \\ with the assistance of \\ Lieutenant-Commander J. F. Gruning, D.S.C., R.N. ${ }^{2}$ \\ (Plates I-IV and Text-figs. I-9)
}

[This paper is published with the approval of the Lords Commissioners of the Admiralty, but the responsibility for any statements of fact or opinions expressed rests solely with the authors.]

\section{INTRODUCTION}

The purpose of this paper is to review the results obtained from a programme of continuous current measuring at the Seven Stones Lightvessel which lasted for upwards of 600 days. It is expected that the actual records amassed during that considerable period will be published in due course. For the present, reviews such as this are being prepared and published seriatim in advance of any major presentation of the detailed data.

This present paper follows shortly upon an earlier one, the subject matter of which was information entirely comparable in nature but very much less in extent. The briefer paper (Carruthers \& Lawford, 1950) dealt with the water movements past the Mouse Lightvessel in the Thames Estuary, and is no. $\mathrm{I}$ in the series.

Marine biologists in general, and fishery research scientists in particular, attach importance to schemes of investigation which produce solid information on water movements adequate in time span to serve studies of the dispersal of passively drifting marine organisms. Because of this, there had come into being, by the time World War II broke out, a wide scheme of observations which aimed at amassing simple data on water flow past an ever-increasing number of lightvessels. The aim was to learn for all days of whole years (without intermissions imposed by bad weather) how a thick surface layer of water had moved at a sufficient number of places in the southern North Sea and the English Channel to produce a synoptic picture of value to workers

1 Royal Naval Scientific Service.

2 Serving with the authors in the Hydrographic Department of the Admiralty. 
concerned with the life histories of fish and other organisms. The information gathered had real interest for others besides, such as engineers concerned with coast erosion, and seamen.

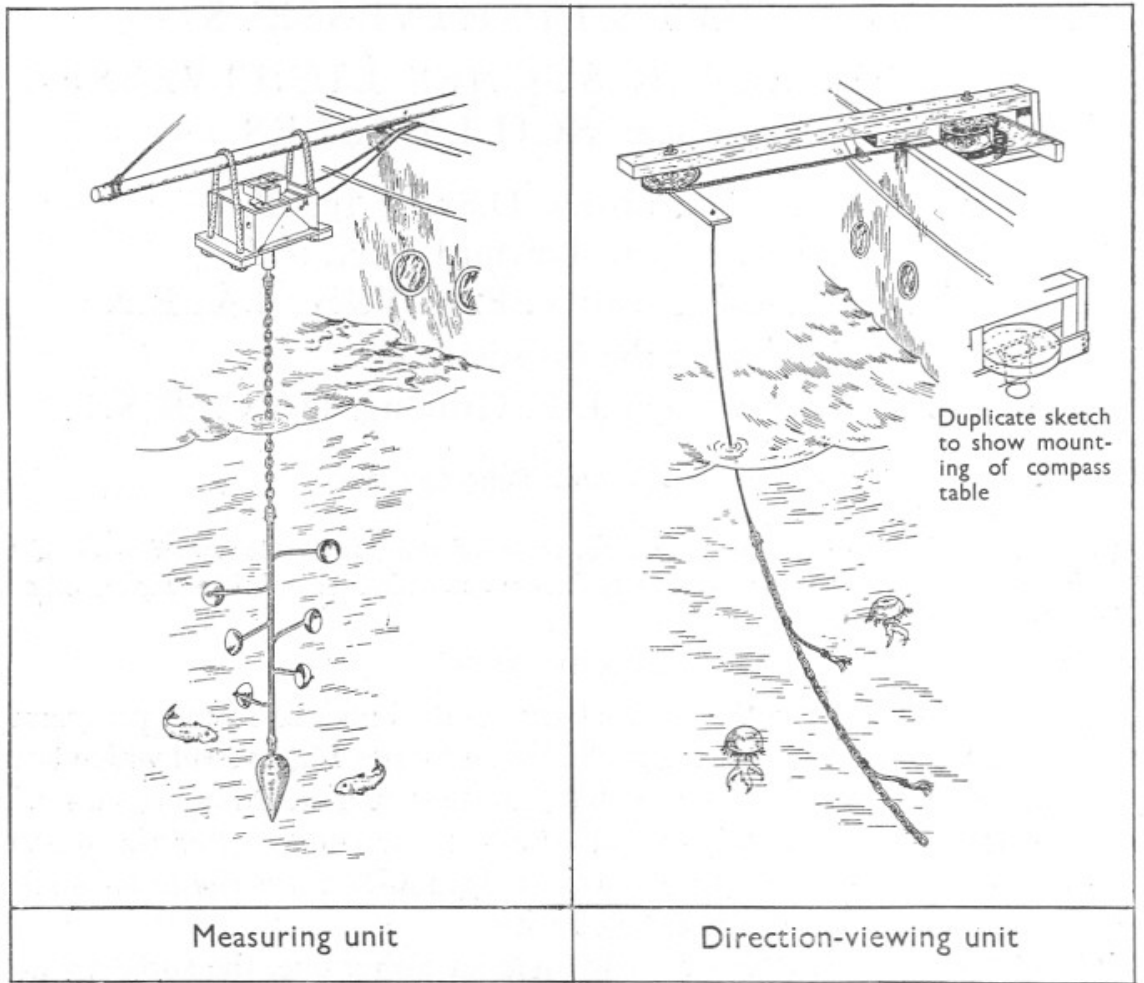

Text-fig. I. The vertical log current meter as used aboard lightvessels. With this extremely robust (but not in this form automatic) instrument, a very large body of data on water-flow past lightvessels has been amassed. The observations have been carried on without any intermissions imposed by wild weather, and, throughout the entire winter of I938-39, 'non-stop' observations were made with this instrument from ten lightships (English, French, Dutch and Danish) in the southern North Sea and English Channel... and also from the Seven Stones lightship near Land's End. A modified form of the instrument can provide for automatic observations from anchored ships, and a special version of it now exists for use from an unattended buoy so that the immobilization of an observing vessel is avoided. The resulting data on water movements are directly applicable to navigational needs because a thick layer of water is investigated; it has been customary to submerge the $5 \mathrm{ft}$. long cup system about I fathom below the sea surface. No considerations of magnetic disturbance arise to prohibit the use of this instrument from steel vessels other than at 'safe' depths, and there is a virtual absence of registration of spurious current from revolutions put on in response to ship movements.

Text-fig. I shows the instrument (the original 'Vertical Log') with which the information was gathered, and its legend tells something about the employed apparatus.

Before the War, it was customary to publish a yearly presentation of the results obtained from the various lightships aboard which the work was in 
train. Such annual publication was made in the pages of the Rapports et Procès-Verbaux of the International Council for the Exploration of the Sea.

When War came, a considerable body of data perforce went unpublished, and to this was added information from such lightships in which it was possible to continue the work. That such continuance into the period of hostilities was sometimes possible was due jointly to the good offices of the Hydrographic Department of the Admiralty, and to the kindness of the English Department of Fisheries, in allowing the senior author not only to continue in possession of the apparatus which he had been using, but also to have the services of his assistant (the late $\mathrm{Mr} \mathrm{R}$. S. Minchin) to run the programme whilst he himself was engaged upon other duties.

Amongst the bodies of unpublished data held when the War ended was that for the Seven Stones Lightvessel. The position in question is perhaps second in interest only to that of the Varne Lightship anchored in the Straits of Dover. The amount of information is by itself noteworthy, and the position concerned has its own particular interest.

Various authors (quoted later) have put forward views on the possible scheme of water circulation in the area off the western entrance of the English Channel and the adjacent region lying off the southern entrance to the Irish Sea. It seemed that the data from the Seven Stones might serve to throw light upon this matter, or at least might provide help to anyone trying to decide whether or not the Rennell Current is a real entity.

In an earlier paper (Carruthers, 1934) the Rennell Current topic was touched upon. At that time it was possible to discuss the results obtained in the course of only 28 days observing from the Seven Stones Lightship.

The instrument then used was not the same, and the depth of observation was greater, but the 1934 results testified to the existence of an overall water movement towards the south-east quadrant of the compass. This direction of residual flow, we shall see, was evidenced by the very much larger body of data to be discussed below.

It was considered that the mass of continuous data available amply merited a measure of detailed study, and it has been deemed worth while to investigate it rather thoroughly in respect of wind influence on water movement.

When the time comes to publish the collection of daily records in extenso, they will probably be presented in a form which lets the associated wind conditions be seen at a glance. It is intended to publish them entered in 'clockface' form, of which a specimen is included here (Text-fig. 2.)

The authors desire to express their thanks to the crew of the lightvessel, by whom the observations were made. 


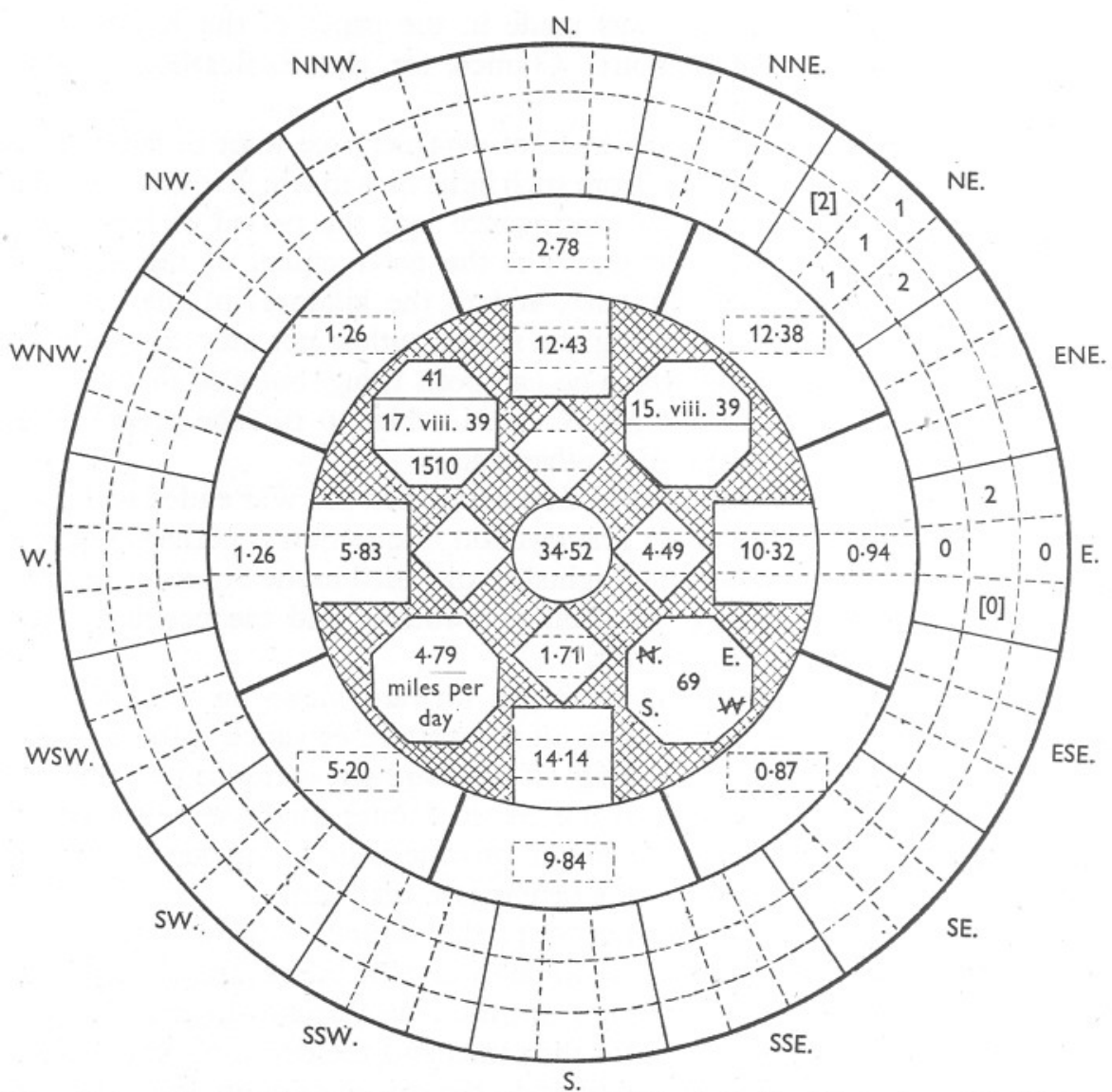

Text-fig. 2. Circular diagram for presenting data (with winds data) from the vertical log.

\section{Explanation of circular diagram}

OUTER RING. (Pecked squares.) The nine wind strengths (Beaufort scale) recorded for the $24 \mathrm{hr}$. upon which the observation is approximately centred.

INNER RING. The water movement in sea miles recorded against each octant during the day. SQUARES. The gross cardinal components of the latter.

DIAMONDS. The net values of the cardinal components.

CIRCLE. The total water movement.

OCTAGONS. Top left-from top to bottom the serial number, date and mid-time of the particular observation.

Top right - the date of the nearest new moon in the upper half or of the nearest full moon in the lower half

Bottom left-the magnitude of the residual water movement.

Bottom right-the direction of the residual water movement.

\section{The OBSERVATIONS}

Observations were commenced aboard the Seven Stones Lightvessel on 4 July I939, when she was in a position $50^{\circ} 03 \cdot 3^{\prime} \mathrm{N} ., 6^{\circ} 05^{\prime} \mathrm{I}^{\prime} \mathrm{W}$. After some 4 months (20 November) the vessel was moved to a position $50^{\circ} 03.5^{\prime} \mathrm{N}$., 
$6^{\circ} 05^{\prime} \mathrm{I}^{\prime} \mathrm{W}$.; observations were, of course, interrupted during the move, but otherwise the change of position, which only amounted to 2 cables, does not seem to have disturbed the sequence of the recorded data. Work was resumed at the new position on 2I November 1939, and continued until I May I94I, when the vessel was withdrawn owing to the war situation.

For various reasons breaks in the observations occurred on nineteen occasions, including the one referred to above. In all, 624 observations, each lasting one lunar day, were made (although 625 observations are listed, serial numbers I32 and I33 only produced sufficient data for one observation owing to an error in the timing of the observations).

The Seven Stones Lightvessel lay in a mean depth of 40 fathoms about 2 miles to the north-eastward of the Pollard Rock, one of the Seven Stones. This position is some I4 miles due west of Land's End and I2 miles northeast of St Mary's (Scilly Isles). The passage between land and land is 22 miles wide, the mean depth being about 36 fathoms (see Text-fig. 3).

Water movements at this position were recorded on all eight octants, but the overall or residual movement was principally east-south-easterly.

During the period under review the centre of the cup system of the measuring unit was $2 \mathrm{I} \mathrm{ft}$. below the sea surface. The water-layer in which observations were taken was from 3 to 4 fathoms below the surface.

The wind was estimated every $3 \mathrm{hr}$., the strength being recorded in Beaufort scale numbers. When the local tractive effect of the wind is considered in this paper, sight is not lost of the fact that the observations relate to a water-layer well below the surface.

The total revolutions, and the revolutions of the eight individual octant counters, per lunar day, were simply obtained by subtracting the readings of the day before. The total daily revolutions and the sum of the revolutions on the octants agreed to within twenty-two revolutions, on the average, though very much larger discrepancies occasionally occurred. This average disagreement represents $\frac{1}{2} \%$ of the total revolutions, and was presumably due to the time lost in changing over the octant counters.

The water movement in sea miles per lunar day was obtained by applying the 'calibration constant' of the instrument to the revolutions. In this case, 300 revolutions were the equivalent of I mile $(6080 \mathrm{ft}$.) of passing water.

The mean wind for the day was calculated by geometrically averaging the winds recorded between the initial and final readings of the counters each day.

A plot of the total water movement showed a strong resemblance to a tidal cycle, with maxima occurring from I to 3 days after full and new moon (see Pls. I and II). A smooth and regular curve could be drawn through a large percentage of the points.

Superficially, a plot of the magnitude of the residual water movement showed much less tendency towards regularity, but comparison with the total 


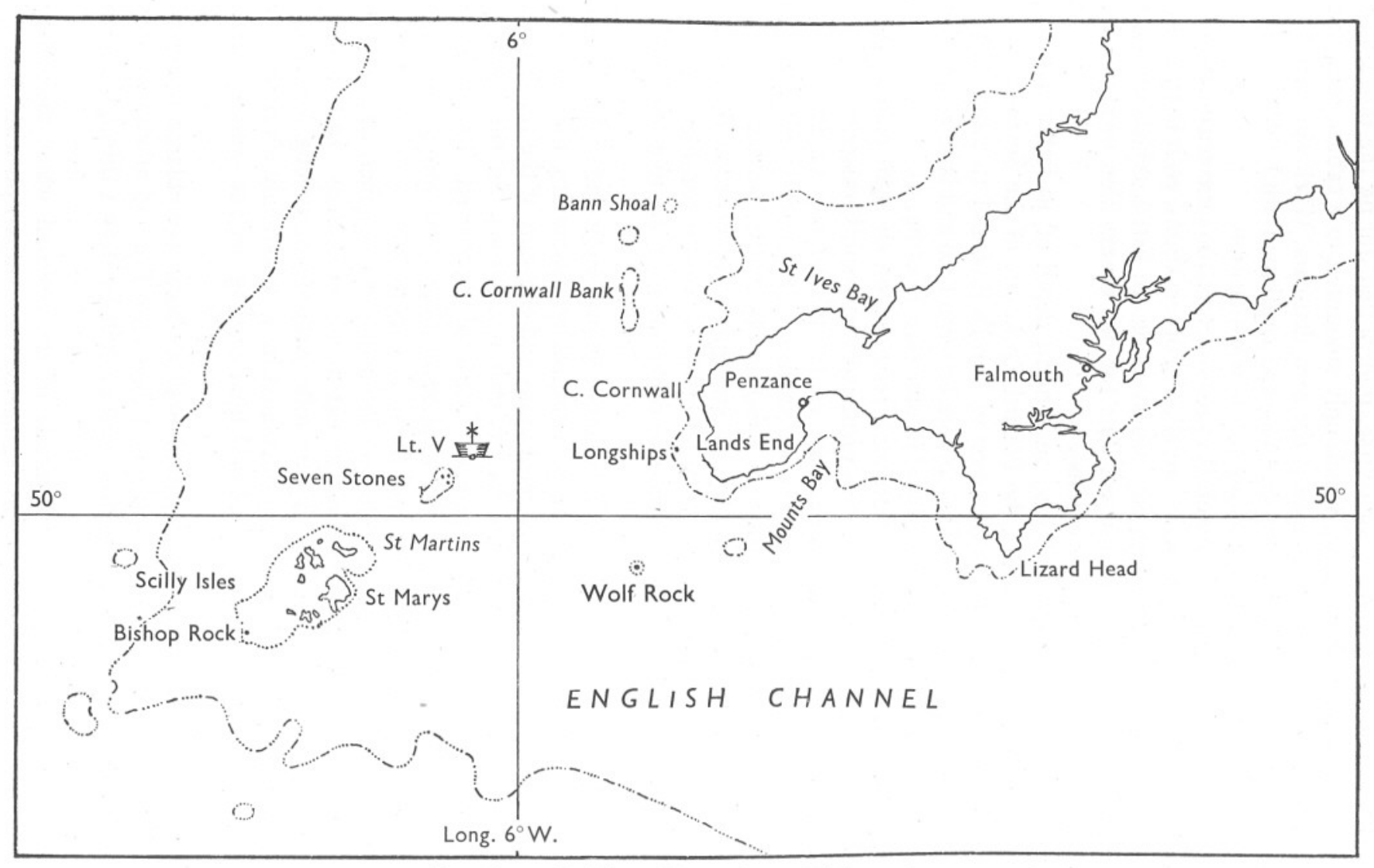


water-movement plot revealed that it was periodic, with marked minima and with double maxima spaced on either side of the total water-movement maxima. A regular curve was also superimposed upon this plot.

(For details of the method of construction of these regular curves, see below, p. 6oI).

A plot was also constructed of the magnetic direction of the residual water movement, centred approximately on the mean for the whole period.

As a first step in analysis, the monthly averages of water and wind movements (shown at the tops of Pls. I and II) were investigated, as these gave reasonably smoothed values for comparison over approximately equal periods of time. It was found that the following conditions of water movement obtained in association with the mean residual wind:

(a) Larger total water movements than usual were associated with winds from east, through south, to west-north-west, while smaller movements than usual were associated with winds from other directions. 'Doubtful' sectors existed on the boundaries between the two areas. Also, lower total water movements occurred when the residual wind velocities were medium (4-8 m.p.h.), and higher when the wind velocities were both low (o-4 m.p.h.) and high (8-I2 m.p.h.).

(b) Above average residual water movements were associated with winds from south-south-west to north-west, and below average movements with winds from north-west to east-south-east; when the wind was between east-southeast and south-south-west the residual water movement was of average magnitude. Also, the residual water movements tended to be lower than usual with medium winds and higher than usual with light and strong winds.

(c) In association with winds from north-east, through south, to southsouth-west the direction of the residual water movement was displaced to the north of the mean for the whole period; with winds between south-west and north-north-east the direction was displaced to the south. When winds were from the small sectors between these major arcs the direction of the residual water movement remained average. Also, there seemed to be some tendency for light winds to be associated with the average direction, medium winds with a displacement to the south and strong winds with a displacement to the north of the average. Between the two last-named wind-speed groups, however, was a band where the direction was again average. There was also a single indication that a residual wind above 12 m.p.h. was associated with a displacement to the south of the average.

(It must be emphasized that those conclusions which are derived from wind strength are by no means as firm as those derived from wind direction.)

The monthly averages are illustrated graphically in Text-fig. 4, and the findings in Text-fig. 5 .

The above findings were checked by inspection of the plotted observations of wind and water movements for individual days or groups of days, and were 


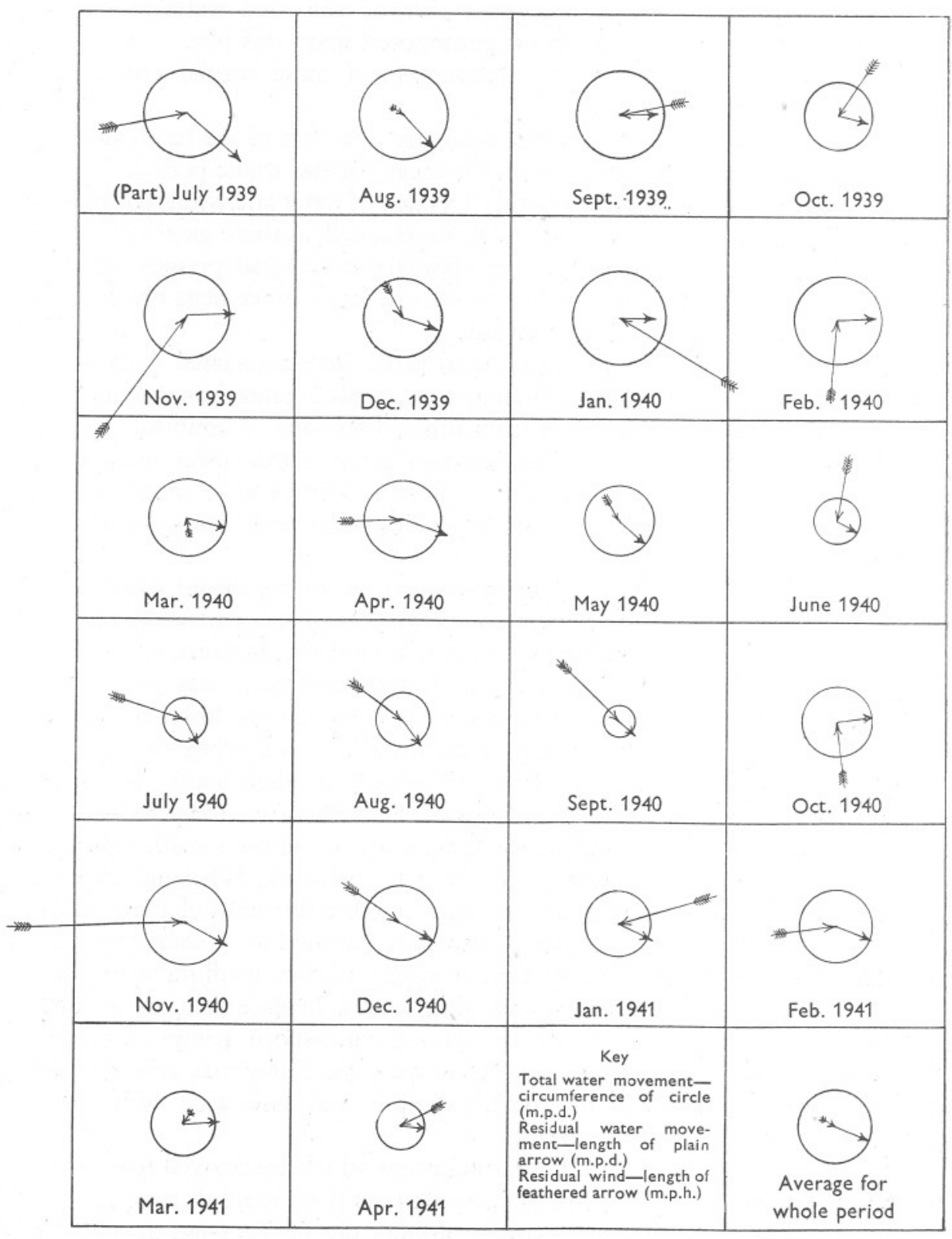

Text-fig. 4. Monthly averages of total and residual water movement and residual wind. (All directions are true-variation $13^{\frac{1}{2}}{ }^{\circ} \mathrm{W}$.) 


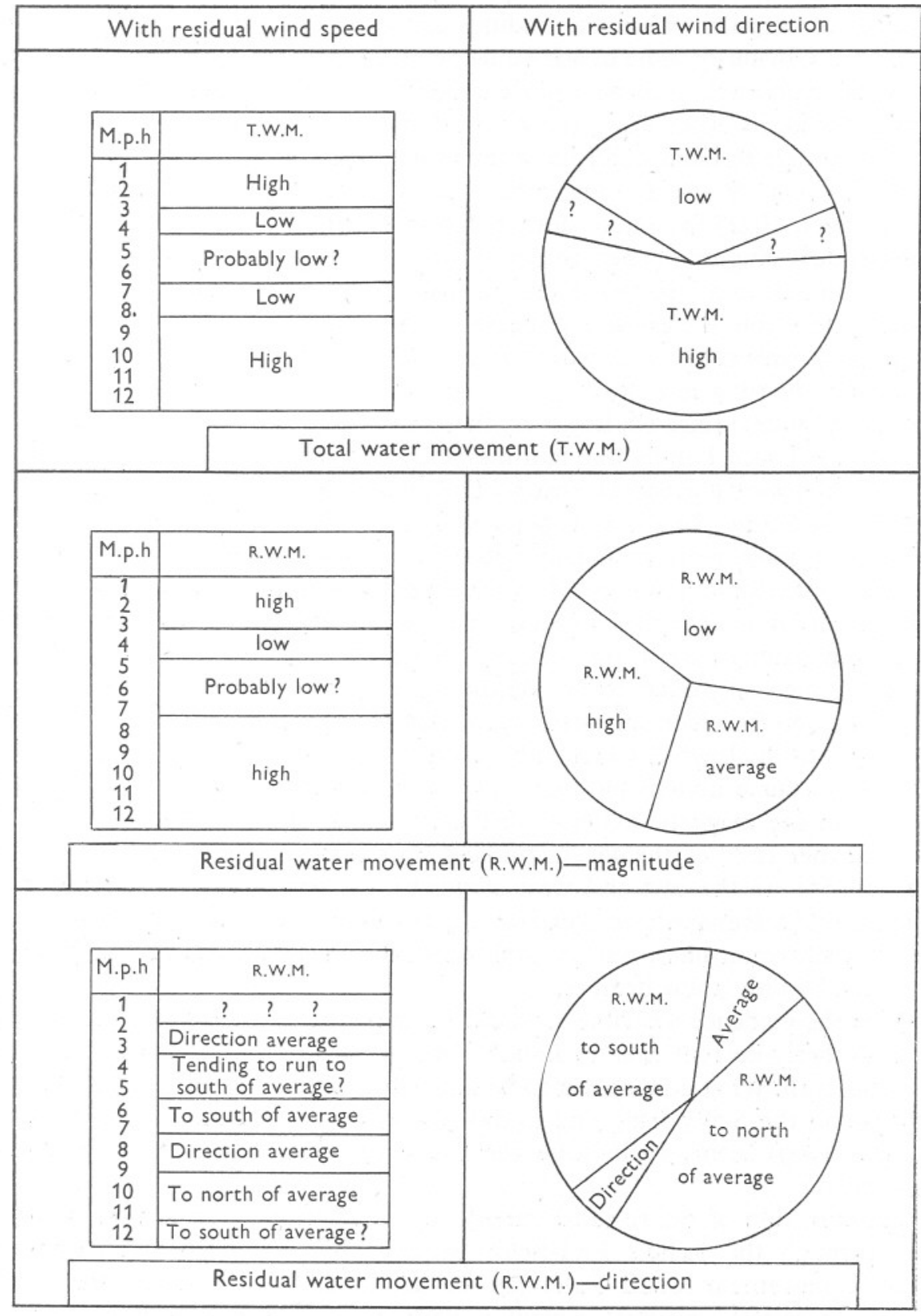

Text-fig. 5. Association of water movements with wind. (All directions are true-variation $13 \frac{1}{2}^{\circ} \mathrm{W}$.) 
found to agree reasonably closely, although it is not denied that there are a number of occasions when the findings appear to be in direct opposition to the facts. Obviously some unknown factor, such as the wind at some distance from the lightvessel, must have made its influence felt, and on these occasions, it is assumed, its effect was greater than that of the local wind.

The average residual water movement over the whole period was 2.5 m.p.h. in a direction S. $56 \frac{1}{2}^{\circ} \mathrm{E}$. (magnetic) $=\mathrm{S}$. $70^{\circ} \mathrm{E}$. (true). In an earlier paper (Carruthers, 1934) the senior author calculated, from twenty-eight observations made in August and September of 1933, that the residual water movement was $\mathrm{I} .9 \mathrm{~m}$.p.d. in a direction S. $20^{\circ} \mathrm{E}$. (true). Obviously these earlier figures differ widely from the average of the observations here discussed; nevertheless, they agree reasonably well with the monthly averages for the August and September of 1939 and 1940.

Harvey (I924) indicated, however, that there was a northward movement of the water between Land's End and the Scilly Isles, and in a diagram showed a north-north-west movement close to Land's End forming part of a cyclonic flow round Scilly. In a later paper (I929) he stated that there was a northnorth-west movement at a daily speed of $I_{2} \frac{1}{2}$ knots at a depth of $60 \mathrm{~m}$., and that a cyclonic flow existed in the upper layers as a component of the currents at $60 \mathrm{~m}$. Matthews (I9I3), who was quoted by Harvey, remarked that the northerly current passed only a few miles to the westward of Land's End. A noteworthy reference by Matthews, however, was to a paper published by Dr Bassett in which the latter stated that water from the Bristol Channel escaped into the English Channel between Scilly and Land's End.

It is of course undeniable that $13 \%$ of the observations show a residual current in the magnetic octants north-west, north and north-east, and that on a further $12 \%$ of the days it pursues courses between the limits of these octants $\left(67 \frac{1}{2}^{\circ}\right.$ to the east and west of north) and east and west (magnetic). The monthly averages (see Text-fig. 4), however, show that during only 5 months, all winter ones, was the residual current to the north of east (true), and then by only a few degrees.

With the evidence available it would be impolitic to dispute the existence of a northerly current close to Land's End (some I2 miles distant) and at a greater depth. What does appear to be somewhat more doubtful is the cyclonic flow round the Scilly Isles, and in this connexion information obtained from Tizard (I909) seems to indicate the existence of an anti-cyclonic residual movement.

The direction of the residual current at the Seven Stones is more across than through the Land's End-Scilly passage. If the existence of an anticyclonic movement round Scilly can be accepted, it is suggested that the east-south-easterly residual current is perhaps an offshoot of this system which turns further to the north as it crosses the passage and finally joins the north-going flow north of the Longships. It is only fair to state, however, 
that Tizard's logship observations also indicate a south-easterly residual current at three positions to the south-east of the Seven Stones. On these grounds the inference is that the residual current at the Seven Stones Lightvessel is, in fact, part of a general south-easterly flow through the passage.

Text-fig. 6 illustrates the possible circulation referred to above. The water movements are the resultants of the figures given in the tables by Tizard, assuming that the hourly observations represent the average movement for an hour.

In the study of water movements it is probably unsafe to draw analogies, but there does seem to be a certain similarity between the current systems in the North Sea and in the neighbourhood of the Scilly Isles. In the former, a north-easterly current emerges from the Straits of Dover, continues along the coasts of the Low Countries, turns more to the north off the Danish coast and finally escapes from the North Sea in a north-north-westerly direction after skirting the coast of Norway. Part of the north-westerly water movement to the west of the British Isles turns clockwise to the north of the Shetlands to enter the North Sea in a southerly direction. Some of this water turns to the eastwards to flow past the vicinity of the Fisher Banks and join the northgoing movement along the Norwegian coast.

In the Scilly area, there are the east-north-easterly current up-Channel to the south of the area and the northerly current close to Land's End, while to the northward water enters the Bristol Channel from the southwest. If the analogy has force, the east-south-easterly water movement at the Seven Stones is the counterpart of the current in the Fisher Banks area. Until data are available of water movements in other positions in the vicinity, however, suggestions such as these must perforce be in the nature of speculation.

Turning to the plotted information, there are notably small minimal total water movements (less than I mile per day) between the end of July and the end of September 1940. Minimal total water movements of less than 4 miles a day also occur in October I939, and January, March and April I94I. These minima are not associated with any particular wind direction nor, with the exception of the one occurring in January I94I, with particularly strong winds.

This was considered sufficiently striking to warrant calling upon the local knowledge of the lightvessel personnel, and a letter of inquiry was accordingly addressed to the competent Trinity House authority.

In his reply to the Chief Superintendent of Trinity House, one of the masters of the lightvessel (Mr D. Appleby) remarks that on some days a $2 \mathrm{lb}$. lead can be kept on the bottom during the whole of the tidal cycle, flood and ebb. Bearing in mind how very little water movement is necessary, in 40 fathoms, to take such a light weight off the bottom, it can safely be assumed that the tidal stasis on such occasions extends from the surface to the sea-bed. $\mathrm{Mr}$ Appleby adds that these periods occur during neap tides, especially when the succeeding spring tides are not 'very hot', providing weather conditions 


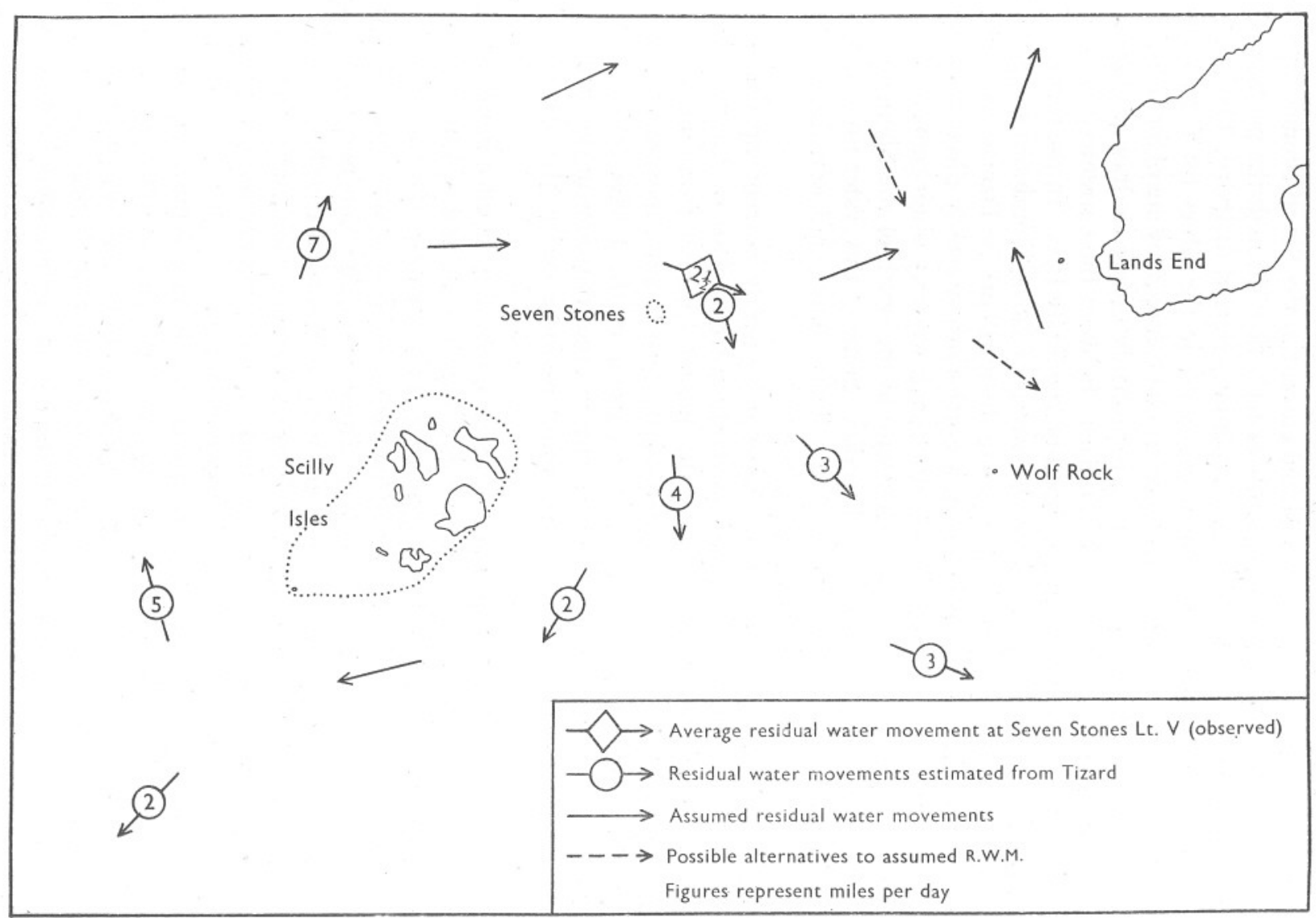


are normal. A glance at the plotted observations for the dates referred to will show that Mr Appleby's statements are in good agreement.

Scrutiny of the plotted record of total water movement will also reveal that, if a smoothed curve were drawn through it, the resultant curve would exhibit sinusoidal characteristics. It is suggested that the minimal total water movements coincide with the minima of such a smoothed curve, which occasionally approaches very close to the zero line, and that they are therefore regular and would be predictable occurrences. Indeed $\mathrm{Mr}$ Appleby predicts in his letter, which was written in I947, that minimal movements would occur on about 24 or 25 September of that year; unfortunately there are no records to confirm this. It appears possible that the period of these minima is about twice yearly, and that they have alternate higher and lower values.

A further point of interest arises in connexion with the plotted observations of residual current direction. Nearly always the direction changes, usually in a marked manner, from one side of the mean to the other at, or shortly after, the minima of the total water movement (i.e. neaps). This shift is mostly from south to north of the mean direction. At about the time of springs there is a shift to the south of the mean, but this movement is very much less marked and may take some days to accomplish. The shifts may sometimes be of degree and not of 'sign'. Viewed in this light, the otherwise irregular plot of residual current direction exhibits ' $s$ w-tooth' characteristics with reasonably well-marked periodicity.

Again, if a smoothed curve were drawn through the residual currentdirection plot, the resultant curve would oscillate from side to side of the mean direction. From Pl. I, which covers I year, it is tempting to assume that the oscillation is annual, with maximum northerly deflexion in winter and maximum southerly in summer, but Pl. II, for the succeeding Io months, does not confirm this, and the point must await the collection of more data.

\section{SUMMARIZED RESULTS}

A survey of the water and wind movements recorded during the 624 days of observing at the Seven Stones Lightvessel brings the following facts of chief interest to light:

(i) Water moved towards all octants of the compass.

(ii) The maximum/average/minimum values of the total water movement (the summed daily mileage of the travel in all eight octants) were $39 \cdot 7 / 15 \cdot 0 / 0 \cdot 2$ miles/day.

(iii) The daily water movements in the individual octants are given in miles per day in Table I.

Octant (magnetic)

Maximum

Average

Minimum

\section{TABLE I.}

$\begin{array}{lrlrrrrc}\text { N. } & \text { N.E. } & \text { E. } & \text { S.E. } & \text { S. } & \text { S.W. } & \text { W. } & \text { N.W. } \\ 5 . \mathrm{I} & \mathrm{I} 3.7 & 5.8 & 5.4 & 14.7 & 7.3 & 5.5 & 3.7 \\ \mathrm{I} .3 & 3.8 & \mathrm{I} \cdot 2 & \mathrm{I} \cdot 2 & 4.0 & \mathrm{I} .5 & \mathrm{I} \cdot 0 & 0.9 \\ 0.0 & 0.0 & 0.0 & 0.0 & 0 . \mathrm{I} & 0.0 & 0.0 & 0.0\end{array}$


(iv) The maximum/average/minimum residual current (the net travel or 'overall make' of the water) and its direction of flow (magnetic) were:

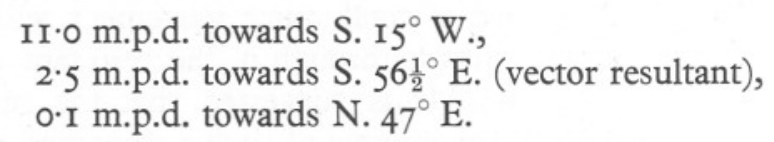

(v) The residual water movements in the individual octants are given in miles per day in Table II, together with the percentage frequency with which they occurred.

\begin{tabular}{|c|c|c|c|c|c|c|c|c|}
\hline \multirow[b]{2}{*}{$\begin{array}{c}\text { Octant } \\
\text { (magnetic) }\end{array}$} & \multicolumn{6}{|c|}{ TABLE II } & \multirow[b]{2}{*}{ W. } & \multirow[b]{2}{*}{ N.W } \\
\hline & N. & N.E. & E. & S.E. & S. & S.W. & & \\
\hline Maximum & $4 \cdot 6$ & IO.I & $10 \cdot 0$ & $8 \cdot 7$ & II $\cdot O$ & $5 \cdot 8$ & $4 \cdot 0$ & $\mathrm{I} \cdot 2$ \\
\hline Averag & 2 . & 3.6 & 3. & 3.4 & 3.7 & I. & $2 \cdot 0$ & 0.8 \\
\hline Minimum & $\mathrm{I} \cdot 4$ & $0 . I$ & 0.3 & $0 \cdot \mathrm{I}$ & 0.6 & 0.1 & 0.4 & 0.4 \\
\hline Frequency $\%$ & $\mathrm{I} \cdot \mathrm{O}$ & II $\cdot 4$ & $27 \cdot 4$ & $29 \cdot 6$ & $26 \cdot 3$ & $3 \cdot 2$ & 0.5 & 0.6 \\
\hline
\end{tabular}

(vi) The maximum/average/minimum residual wind, expressed as a vector resultant for a whole day, and its direction, were:

$$
\begin{aligned}
& 38.5 \text { m.p.h. from north-west by north (magnetic), } \\
& \text { I. I m.p.h. from west-north-west (magnetic). } \\
& \text { Nil }
\end{aligned}
$$

(vii) The residual winds on the individual octants, expressed as a mean for a

\begin{tabular}{|c|c|c|c|c|c|c|c|c|}
\hline & & & & & & & & \\
\hline (magn & N. & N.E. & E. & S.E. & S. & S.W. & W. & N.W. \\
\hline Maximum & $3 \mathrm{I} \cdot 3$ & $29 \cdot 6$ & $35 \cdot 8$ & $3 I \cdot 3$ & $36 \cdot 2$ & 33.6 & $30 \cdot 8$ & 38 \\
\hline Average & $9 \cdot 0$ & $13 \cdot 3$ & I3. & I2. & I3. I & II 99 & 12.4 & II $\cdot$ I \\
\hline Frequency & II $\cdot I$ & $10 . \mathrm{I}$ & & 8.8 & $8 \cdot 0$ & $14 \cdot 6$ & 14.9 & $I 8 \cdot I$ \\
\hline
\end{tabular}
whole day, are given in miles per hour in Table III, together with the percentage frequency with which they occurred.

In addition, there was no wind on I day, and on 2 days the vector resultant of the winds was nil (0.5\% frequency).

\section{CORRELATION BetWeEN WIND AND Water MOVEMENT}

In order to study graphically the effect of an outside influence (the wind) on daily water movement it is first essential to construct some form of ideal curve. The latter is defined as that curve which will pass through all the readings of water movement/time (graphically plotted) should external factors be neglected and only the effect of spring and neap tides be considered. A number of such ideal curves were constructed during the analysis of the Seven Stones data. The final object was to produce an ideal residual water-movement curve which would enable large deviations of the actual readings from this curve to be studied in conjunction with a graphical representation of wind strength and direction. Results in one form or another would then be obtainable, but the 
accuracy of the deductions drawn from these results would naturally be dependent upon the accuracy of the ideal curve.

The residual water movement in general showed a definite tendency towards periodicity, and therefore Fourier analysis would show it to be composed of an infinite number of harmonics of a fundamental curve. Very few of these harmonics can be introduced into an ideal curve because of the difficulty of their construction, and indeed most of the harmonics are spurious, being explicable in terms of wind and other effects.

From the water-movement data the following components were obtainable:

(i) Total water movement for the whole day over the octantal headings.

(ii) Residual water movement in strength and direction.

(iii) $N+S$ and $E+W$ components of the total water movement.

(iv) $N \sim S$ and $E \sim W$ components of the residual water movement.

(Note. All the above water movements were measured in sea miles per lunar day.)

The $N+S$ and $E+W$ components of the total water movement were first plotted (see Pls. III and IV) and the two resultant shapes studied (plots K and L). It was found that the springs and neaps were readily discernible and that their total periods were equal to $28 \pm$ I lunar days. In accordance with tidal analysis it was assumed that the two ideal wave forms required were each composed of two waves, one of period 28 days and the other of half-yearly period. On this assumption two smooth curves were drawn for the $N+S$ and $E+W$ components (curves $\mathrm{K}$ and $\mathrm{L}$ ) and were found to pass through approximately one-third of the points.

Since the readings of the vertical log current meter were taken on the octantal headings the following relationships hold:

$(N+S$ component $)$ of the total water movement $=N+S+0.7(N E+S E+$ $N W+S W)$ readings.

$(E+W$ component $)$ of the total water movement $=E+W+0 \cdot 7(N E+S E+$ $N W+S W)$ readings.

Therefore: ( $N+S$ component) together with $(E+W$ component),

$$
\begin{aligned}
& =N+S+E+W+\mathrm{I} \cdot 4(N E+S E+N W+S W) \\
& =\text { total water movement (plot E) }+0 \cdot 4(N E+S E+N W+S W) .
\end{aligned}
$$

With the negative correction term $0.4(N E+S E+N W+S W)$ applied, the ideal curve for the total water movement (curve E) was obtained from the $N+S$ and $E+W$ component curves. This curve was later studied in conjunction with the wind.

In the same manner the readings for the $N \sim S$ and $E \sim W$ components of the residual water movement (R.W.M.) were plotted for magnitude and direction. On studying the two shapes obtained (plots $M$ and $N$ ) it was found that the movements were periodic as before. However, in most cases where there was a maximum in the $(N+S)$ or $(E+W)$ curves there was a minimum in the 
$N \sim S$ and $E \sim W$ plots. It was therefore deduced that a maximum component of total movement did not mean a maximum component of residual movement, but rather a maximum change in magnitude (a change in direction being regarded as a further change in magnitude). Thus for every maximum in a total component curve there would be two maxima and one minimum in the corresponding residual component curve. Assuming this, and that the waves comprising the ideal curves were again of periods 28 days and half yearly, curves $\mathrm{M}$ and $\mathrm{N}$ were drawn for the $N \sim S$ and $E \sim W$ residual components. The wind appeared to have a greater effect on the component water movements and the ideal curves passed through only one quarter of the points.

Resolving vectorially, the resultant residual water movement is equal in magnitude to

$$
\sqrt{ }\left[(N \sim S \text { comp. })^{2}+(E \sim W \text { comp. })^{2}\right],
$$

and therefore its ideal curve (curve G) could then be constructed from the two component curves. The actual residual readings were then plotted with respect to magnitude only (plot G) and the ideal curve was found to be in fair agreement.

Finally, the wind was analysed into $N \sim S$ and $E \sim W$ components and its force reverted to Beaufort scale. The two components were plotted in magnitude and direction and the plots $(\mathrm{H})$ studied in relation to large deviations from the ideal curves. The following deductions were made assuming that the non-factual curves were authentic.

On comparing the ideal residual water movement (R.W.M.) curve (G) with the observed plot, it was found that although on the whole there was a definite agreement between the two, for a number of observations there was a marked divergence in magnitude. Considering the ideal curve as a datum, a positive divergence was said to exist if the factual plot was above the curve and a negative divergence if below. Noting the wind components where the divergences occurred, a table of the following form was prepared:

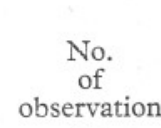

27

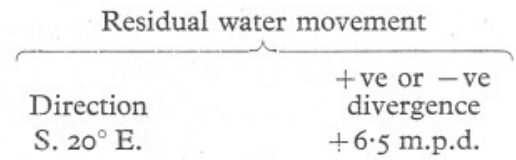

Direction

S. $20^{\circ} \mathrm{E}$.

$\begin{array}{cccc}\text { N. } & \text { S. } & \text { E. } & \text { W. } \\ 2 & - & - & 3\end{array}$

The table was studied with the object of relating the divergences to wind effect. Considering in each case the wind and the direction of the R.W.M. as belonging to one of the quadrants, the frequency of positive and negative divergences was found for each of the quadrants. From this frequency distribution it was discovered that the effect of the wind on the R.W.M. followed a logical hypothesis.

Text-fig. 7 is a diagrammatic representation of wind effect for each quadrant. Considering the north-west quadrant alone, the limits of the wind 


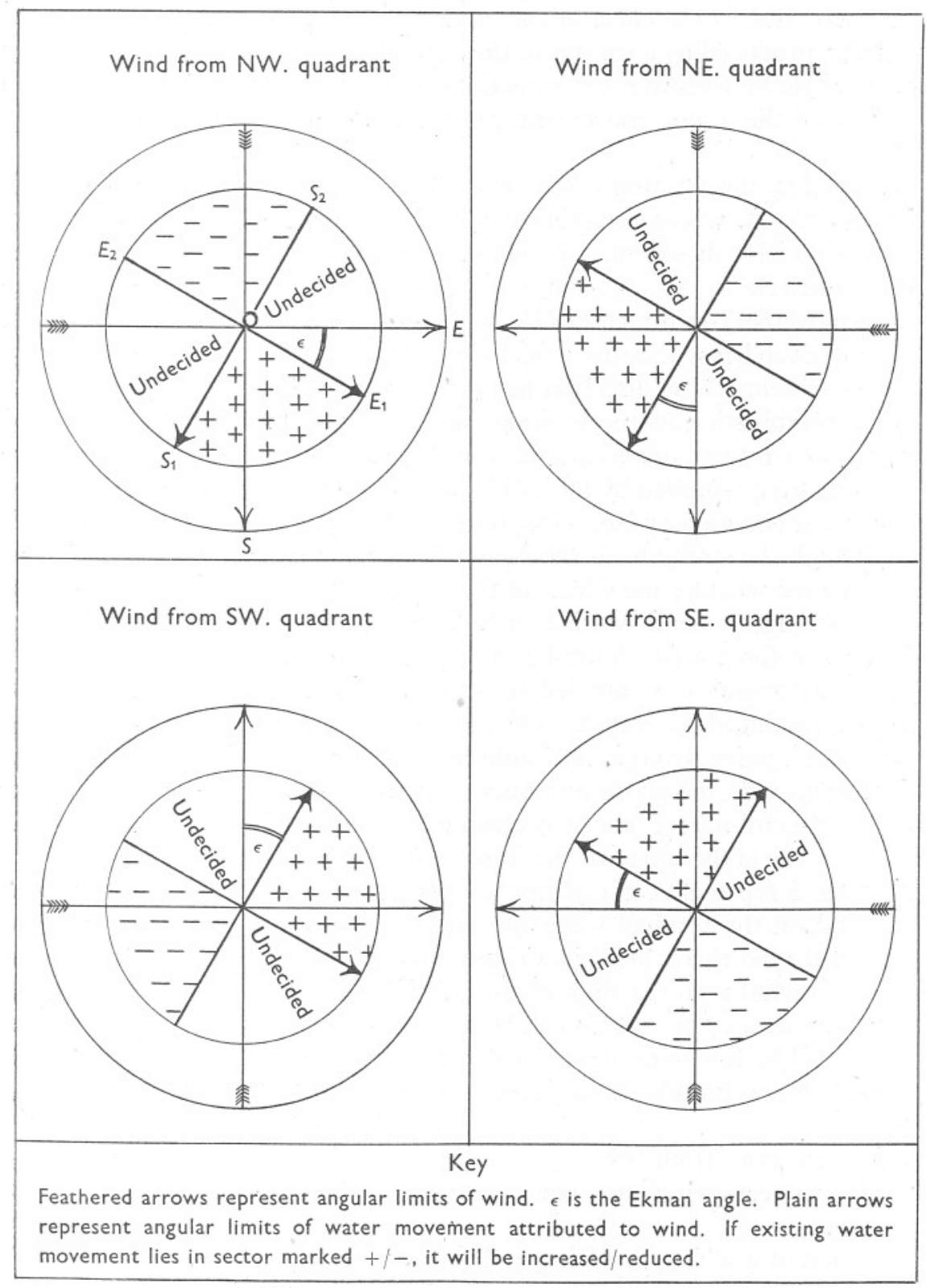

Text-fig. 7. Theoretical effect on residual water movement of winds from various quadrants. 
direction lie along $O E, O S$. Ekman's theory states that for the northern hemisphere, due to the effect of the earth's rotation, the direction of a water movement produced by a wind is to the right of the wind direction. Assuming that the angle between the two directions is of magnitude $\epsilon$, the limits of the direction of the water movement produced by the wind lie along $O E_{1}$, $O S_{1}$.

Considering the limiting cases, a water movement in direction $O E_{1}$ will assist any R.W.M. whose direction lies in the semicircle $S_{1}, E_{1}, S_{2}$, thereby causing a positive divergence. It will oppose any R.W.M. whose direction lies in the semicircle $S_{1}, E_{2}, S_{2}$, and will create a negative divergence. Likewise a water movement in direction $O S_{1}$ will assist any residual water movement whose direction lies within the semicircle $E_{1}, S_{1}, E_{2}$, and will oppose a residual water movement whose direction lies within the semicircle $E_{1}, S_{2}, E_{2}$.

For a combination of the limiting cases, i.e. the effect of a general wind from the north-west quadrant, there will be a definite positive divergence for the quadrant bounded by $O E_{1}, O S_{1}$, and a definite negative divergence for the quadrant bounded by $O E_{2}, O S_{2}$; the other two quadrants will be undecided, for, although the strengths of the $N$ and $W$ components are known, it cannot be ascertained whether the effects of the components are directly proportional to their strengths, i.e. a $N$ wind of force 2 might have a greater effect than a $W$ wind of force 3 (see Text-fig. 5).

These arguments were applied to all four of the wind quadrants and the diagrams produced as shown. Of 180 cases considered, where a definite positive or negative divergence should have occurred, $80 \%$ were found to be in agreement with the above hypothesis. It should be noted that the latter is of a very general nature, and it is again emphasized that its validity depends entirely on the authenticity of the ideal residual water-movement curve.

Text-fig. 8 represents an attempt to explain vectorially the effect of a constant wind on the residual water movement. The only assumption required is that in the northern hemisphere the direction of a water movement produced by a wind is to the right of the wind direction (Ekman's theory). The results from the vector analysis can be used with the ideal R.W.M. curve shown in Pl. III. The following demonstrates that a deduction can then be made regarding the magnitude of the angle between the directions of the wind and the water.

Wind direction $($ from $)=\mathrm{N} . \phi \mathrm{E}$.

Angle between wind and water movement produced by wind (Ekman angle) $=\epsilon$.

Direction of R.W.M. $=$ S. $\rho$ W.

$V_{R}=$ velocity of R.W.M.

$V_{i}=$ velocity of intrinsic water movement, i.e. the water movement if wind had not been present (given by the ideal R.W.M. curve).

$V_{w w}=$ velocity of water movement due to wind. 


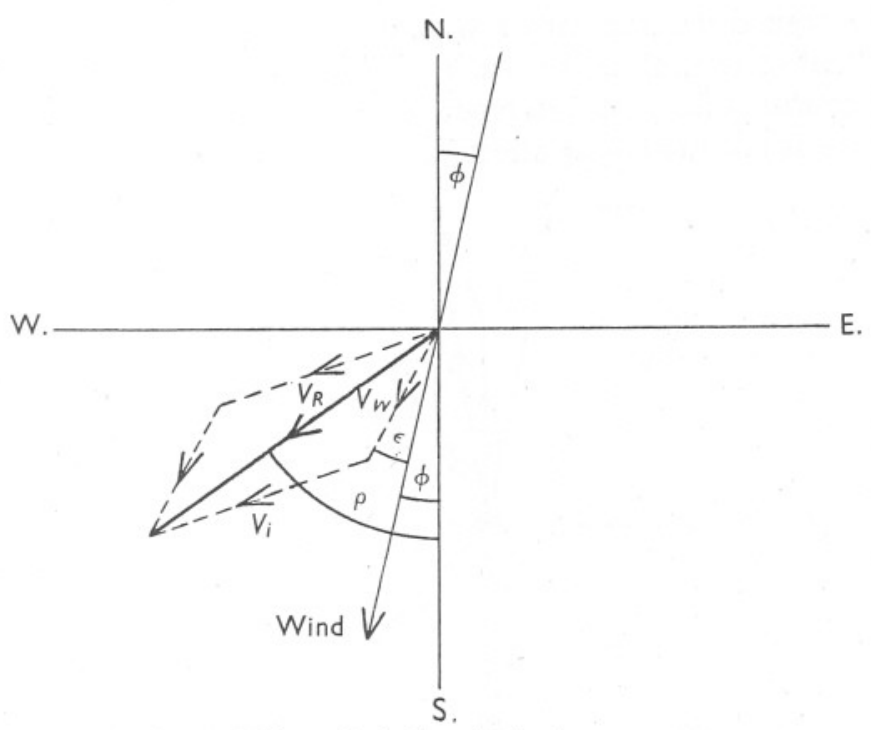

Text-fig. 8. Effect of wind on intrinsic water movement.

Then

$$
V_{R}=V_{i}+V_{w} .
$$

In the triangle of sides $V_{R}, V_{i}, V_{w w}$, the angle between $V_{R}$ and $V_{w}=\rho-(\phi+\epsilon)$. Then

$$
V_{i}^{2}=V_{R}^{2}+V_{w}^{2}-2 V_{R} \cdot V_{w} \cdot \cos (\rho-(\phi+\epsilon)) .
$$

But from Thorade (19I4)

$$
V_{w v}=\frac{\mathrm{I} \cdot 26 \mathrm{~V}}{\sqrt{ }(\sin \lambda)} \text { for winds above Beaufort strength 3, }
$$

where $V=$ wind velocity and $\lambda=$ latitude.

Since $V_{R}, \phi$ and $\rho$ are known and $V_{i}$ is obtainable, $\epsilon$ may be determined.

In (C), $V_{w}$ is in $\mathrm{cm}$./sec. and $V$ in $\mathrm{m}$./sec. Converting to other units and substituting $50^{\circ}$ for $\lambda$ :

$$
V_{v w} \text { (m.p.d.) }=0.35 V \text { (m.p.h.), }
$$

or, water movement $=\mathrm{I} \frac{1}{2} \%$ of wind movement.

Rearranging (B):

$$
\epsilon=\rho-\phi-\cos ^{-1} \frac{\left(V_{R}^{2}+V_{w}^{2}-V_{i}^{2}\right)}{2 V_{R} \cdot V_{w}} .
$$

For a number of observations, the mean $\epsilon$ was found to be $12^{\circ}$ to the right of the wind. This is in accordance with Ekman's theory and supports, to some degree, the validity of the ideal R.W.M. curve. 
It may be argued that the daily R.W.M. does not exist as a single vector, but is the resultant of several vectors each of which are acted upon by the wind. This is, of course, a fact, but reference to Text-fig. 9 will show that the foregoing analysis is not materially affected.

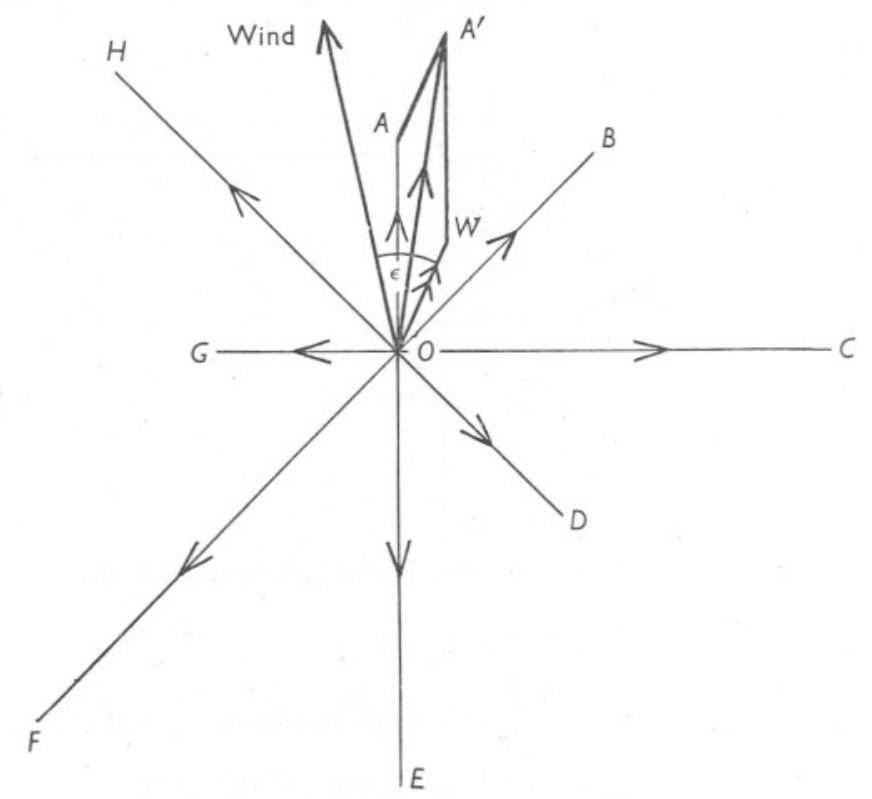

Text-fig. 9. Effect of wind on residual water movement components.

Consider a number of water movements acting at a point $O$. If the R.W.M. be $\mathbf{O R}$, then

$$
\mathrm{OR}=\mathrm{OA}+\mathrm{OB}+\mathrm{OC}+\ldots+\mathrm{OH} .
$$

Now consider another water movement, $\mathbf{O W}$, produced by the wind, acting in conjunction with each. Then

$$
\begin{aligned}
& \mathbf{O A}+\mathbf{O W}=\mathbf{O A}^{\prime} \\
& \mathrm{OB}+\mathrm{OW}=\mathrm{OB}^{\prime} \\
& \mathrm{OH}+\mathrm{OW}=\dot{\mathrm{OH}^{\prime}}
\end{aligned}
$$

If the new R.W.M. be represented by $\mathbf{O R}^{\prime}$, then

$$
\begin{aligned}
\mathbf{O R}^{\prime} & =\mathbf{O A}^{\prime}+\mathbf{O B}^{\prime}+\ldots+\mathbf{O H}^{\prime} \\
& =(\mathbf{O A}+\mathbf{O W})+(\mathbf{O B}+\mathbf{O W})+\ldots+(\mathbf{O H}+\mathbf{O W}) \\
& =\mathbf{O R}+n . \mathbf{O W} .
\end{aligned}
$$


Thus the new R.W.M. is equivalent to the old resultant acted upon by a vector of magnitude $n$. OW.

However, since $\mathbf{O A}, \mathbf{O B}$, etc. do not act for the whole time, but only for times (say) $t_{a}, t_{b}$, etc.

$$
n=\frac{t_{a}+t_{b}+\text { etc. }}{\text { Total time }}=\mathrm{I} .
$$

Therefore, $\mathbf{O R}^{\prime}=\mathbf{O R}+\mathbf{O W}$.

Directly related to the matter of considering the wind as producing a water movement within an area of sea already possessing its own intrinsic movement is the finding of Carruthers (I94I). In the experiments cited, the area concerned was one having tidal streams of continually varying magnitude and direction. It was established beyond any doubt that the winds affected the water movements to a marked degree, not only on the surface but to a depth of several feet. The effect was such that, given a persistent wind from any quarter, the tidal streams were found to produce an overall movement roughly downwind.

\section{SUMMARY}

A review is given of the results obtained from upwards of 600 days of current measuring at the Seven Stones lightvessel during I939-4I. From the plotted observations, an attempt is made to deduce the association between the total daily water movement, irrespective of direction, the residual daily water movement or current, and the mean local residual wind.

The average residual water movement over the whole period was $2 \frac{1}{2}$ m.p.d. towards east-south-east. Statements made by earlier authors regarding the water circulation in adjacent areas are examined, and reconciliations are suggested where they seem to conflict with this finding.

An endeavour is made to correlate the wind and water movement mathematically.

\section{REFERENCES}

Carruthers, J. N., I934. The flow of water past the Seven Stones Lightvessel. Fourn. Mar. Biol. Assoc., Vol. xIx, pp. 92I-30.

- I94I. Some interrelationships of meteorology and oceanography. Quart. fourn. Roy. Meteorol. Soc., Vol. xxviI, No. 291.

Carruthers, J. N. \& LaWford, A. L., I950. Water movements and winds at the Mouse Light-vessel, Thames Estuary. Weather, Vol. v, pp 278-83.

Harvey, H. W., I924. Hydrography of the English Channel. Conseil Int. Explor. Mer, Rapp. Proc.-Verb., Vol. xxxviI, pp. 59-89.

- 1929. Hydrodynamics of the waters south east of Ireland. Fourn. Conseil Int. Explor. Mer, Vol. Iv, pp. 80-92.

Matrhews, D. J., I913. The salinity and temperature of the Irish Channel and the waters south of Ireland. Fisheries Ireland Sci. Invest. I913, No. 4. 26 pp.

Thorade, H., I9I4. Die Geschwindigkeit von Triftströmungen und die Ekmansche Theorie. Ann. Hydrogr., Berlin, Jhrg. xxxir, pp. 379-91.

Tizard, T. H., I909. The tides and tidal streams of the British Islands etc. British Admiralty Manual. 


\section{EXPLANATION OF PLATES}

\section{Plate I}

Water movement and wind at the Seven Stones Lightvessel, July 1939 to July I940.

Plate II

Water movement and wind at the Seven Stones Lightvessel, July I940 to April I94I.

Key to Plates I and II

A: Average total daily water movement during the month, in miles per day.

B: Average residual daily water movement and direction (vector resultant) during the month, in miles per day.

C: Average of mean residual daily wind and direction (vector resultant) during the month, in miles per hour.

D: Full and new moon.

$\mathrm{E}$ : Total daily water movement, in miles per day, i.e. the sum of the water movements in all octants, regardless of direction. The thick line represents the recorded observations; the thin line is the 'ideal' curve.

F: Direction of residual daily water movement, i.e. the vector resultant in all octants.

G: Residual daily water movement, in miles per day, i.e. the resultant of the water movements in all octants. The thick line represents the movement calculated from the recorded observations; the thin line is the 'ideal' curve.

$\mathrm{H}$ : Mean daily residual wind force and direction, in Beaufort scale. The full line represents northerly and southerly winds; the pecked line easterly and westerly winds.

$\mathrm{J}$ : Calendar; the alternate black and white bars represent weeks of seven solar days.

Notes. (i) All miles are 'sea miles' of $6080 \mathrm{ft}$. (ii) All days are lunar days of $24 \mathrm{hr}$. $50 \mathrm{~min}$., unless otherwise stated. (iii) All directions are magnetic.

\section{Plate III}

Components of water movements at the Seven Stones Lightvessel, July I939 to July I940.

\section{Plate IV}

Components of water movements at the Seven Stones Lightvessel, July I940 to April I94I.

Key to Plates III and IV

K: North + south component of total daily water movement, in miles per day.

L: East + west component of total daily water movement, in miles per day.

$M$ : North-south component of residual daily water movement, in miles per day.

$\mathrm{N}$ : East-west component of residual daily water movement, in miles per day.

Notes. (i) All miles are 'sea miles' of $6080 \mathrm{ft}$. (ii) All days are lunar days of $24 \mathrm{hr} .50 \mathrm{~min}$. (iii) All directions are magnetic. (iv) The thick lines represent the movements calculated from the recorded observations; the thin lines are the 'ideal' curves. 
Water $\left\{\begin{array}{c}\text { Totol } \\ \text { Residw }\end{array}\right.$

Wind
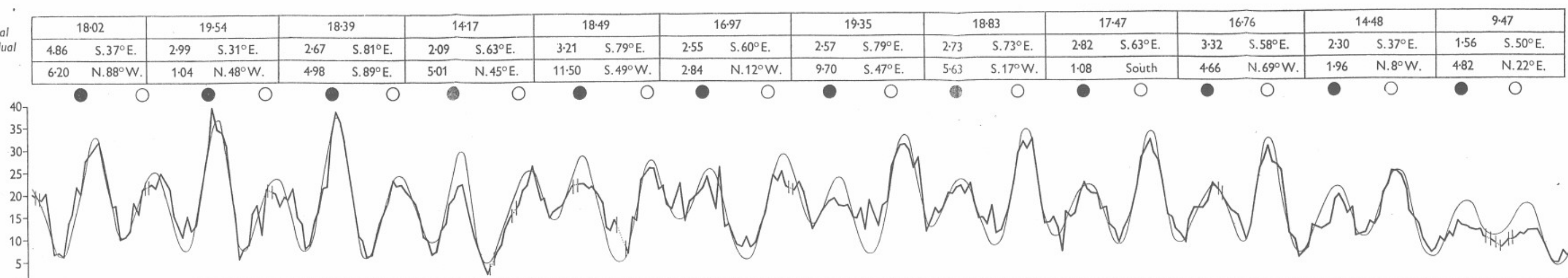

MAM
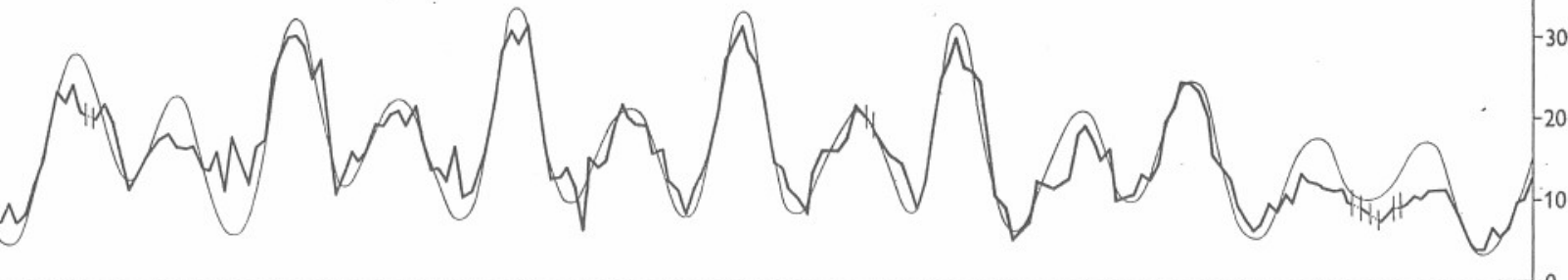

N.-

Direction

E.-
SE.-

S.- $10-$
sw. -
W. - -

G Miles per day

(10)

竞

$\int$

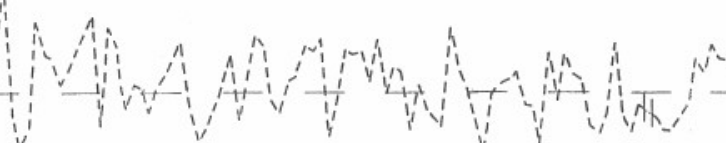

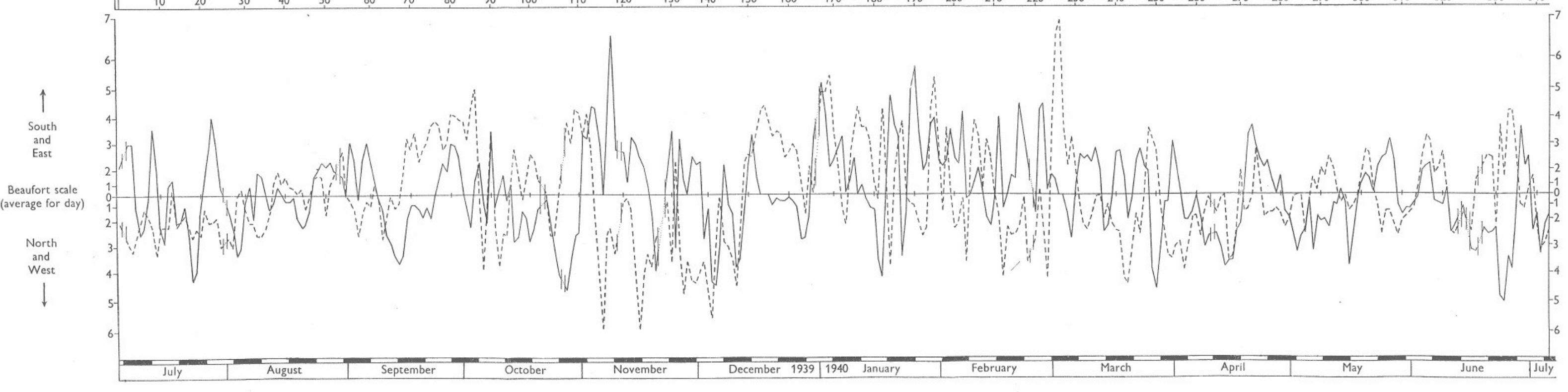


Water $\{$ Toto movement \{ Residud

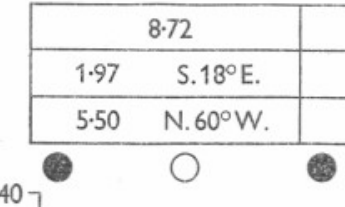

11.70

\begin{tabular}{|c|c|c|c|c|c|c|c|c|c|c|c|c|c|c|c|}
\hline & 7.02 & \multicolumn{2}{|c|}{15.15} & \multicolumn{2}{|r|}{18.80} & \multicolumn{2}{|c|}{$15 \cdot 41$} & \multicolumn{2}{|c|}{$13 \cdot 75$} & \multicolumn{2}{|c|}{$15 \cdot 18$} & \multicolumn{2}{|c|}{$13 \cdot 39$} & \multicolumn{2}{|c|}{9.34} \\
\hline E. & S. $38^{\circ} \mathrm{E}$. & $2 \cdot 30$ & S. $85^{\circ} \mathrm{E}$. & $3 \cdot 12$ & S. $48^{\circ} \mathrm{E}$ & $2 \cdot 74$ & S. $50^{\circ} \mathrm{E}$ & 2.62 & S. $54^{\circ} \mathrm{E}$. & $2 \cdot 48$ & S. $55^{\circ} \mathrm{E}$. & $2 \cdot 50$ & S.79 $\mathrm{E}$. & 1.46 & S. $75^{\circ} \mathrm{E}$. \\
\hline${ }^{\circ} \mathrm{W}$. & $\mathrm{N} .32^{\circ} \mathrm{W}$ & 470 & S. $6^{\circ} \mathrm{W}$. & $12 \cdot 30$ & $\mathrm{~N} .79^{\circ} \mathrm{W}$ & 4.83 & N. $42^{\circ} \mathrm{W}$. & $7 \cdot 40$ & $\mathrm{~N} .86^{\circ} \mathrm{E}$. & 4.44 & N. $85^{\circ} \mathrm{W}$. & $1 \cdot 15$ & N. $54^{\circ} \mathrm{E}$. & 3.79 & N. $75^{\circ} \mathrm{E}$. \\
\hline
\end{tabular}

E Miles per day

$\left.\begin{array}{l}40 \\ 35 \\ 30 \\ 25\end{array}\right]$

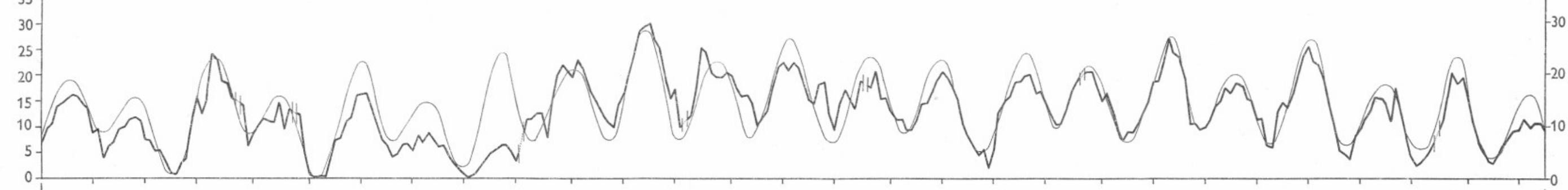

N. -

F Direction $\mathrm{E}$.

NE.-
E. -
SE.-

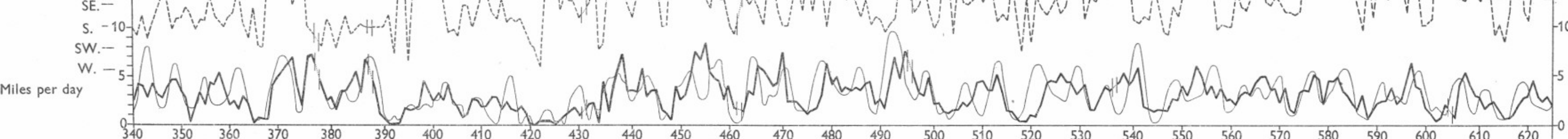

G Miles per day

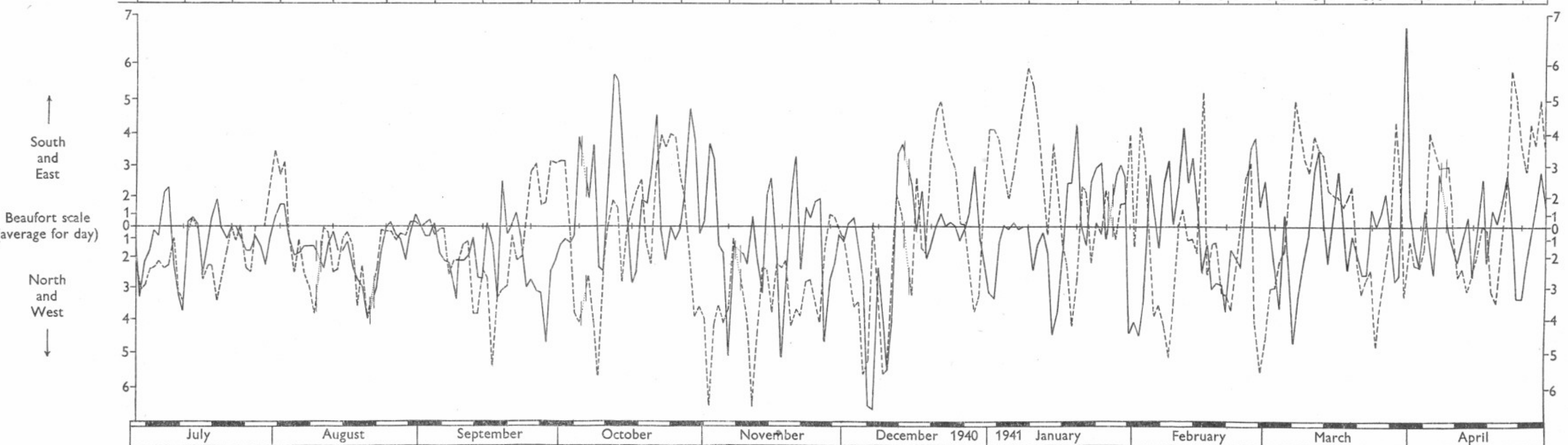




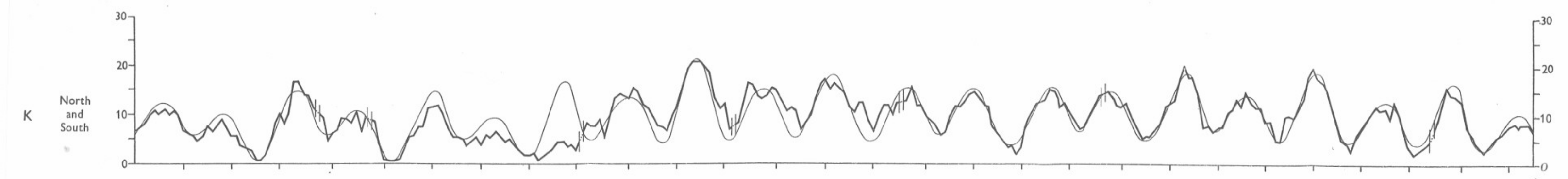

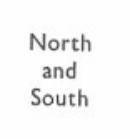

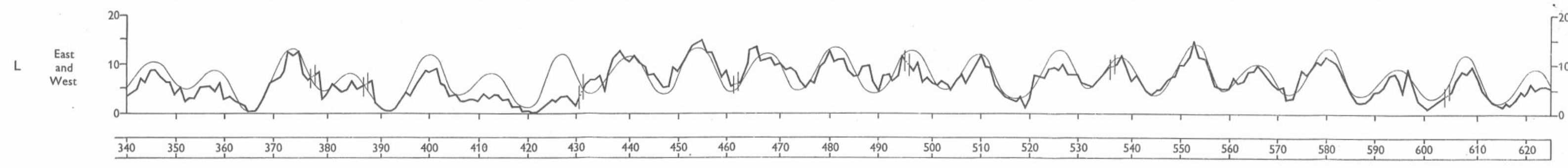

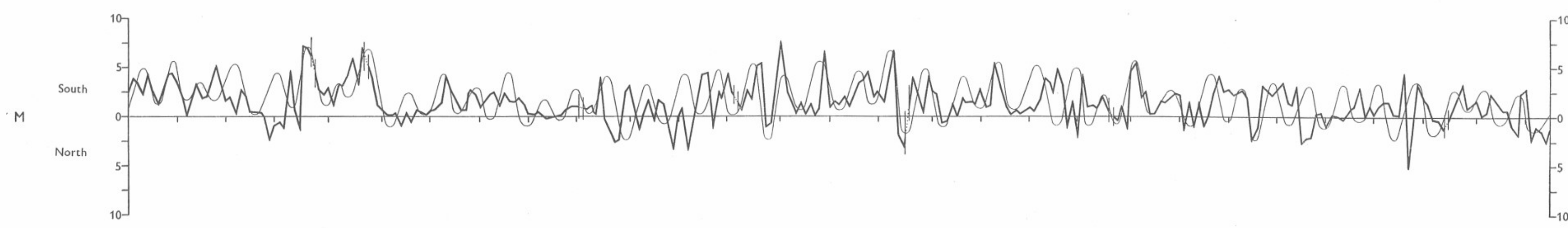
East
and
West

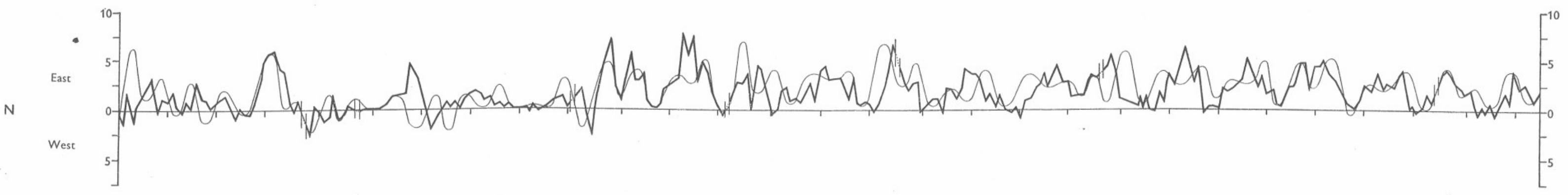

